\title{
Integratie van zorg
}

\section{Inzichten uit (onderzoeks)programma's tussen 2005 en 2017}

\author{
H. J. M. (Bert) Vrijhoef · Caroline A. Baan · Anna Petra Nieboer · Ronald S. Batenburg · Pim P. Valentijn
}

Published online: 23 August 2017

(C) Bohn Stafleu van Loghum, onderdeel van Springer Media B.V. 2017

Om zorg beter te laten aansluiten op de behoeften van individuele zorgvragers kent Nederland diverse (onderzoeks)programma's waarbij integratie van zorg een belangrijke rol speelt. Met dit artikel beogen we lessen uit deze programma's te trekken. Hiertoe beschrijven we op programmaniveau wat de doelen waren (doelen), welke kernactiviteiten zijn verricht (activiteiten), hoe deze zijn geëvalueerd (evaluatie) en welke hoofdaanbevelingen hieruit voortvloeien (aanbevelingen).

Sinds 2005 stuurt het Ministerie van Volksgezondheid, Welzijn en Sport (VWS) aan op een 'programmatische aanpak' van zorg voor mensen met (een risico op) een of meer chronische ziekten [1]. Hierbij han-

\section{Dr. H. J. M. Vrijhoef $(\bowtie) \cdot$ Dr. P. P. Valentijn}

Patiënt \& Zorg, Maastricht UMC+, Oxfordlaan 10, 6229

EV Maastricht, Nederland

b.vrijhoef@mumc.nl

Prof.dr. C. A. Baan

Tranzo, Tilburg University, Tilburg, Nederland

Prof.dr. A. P. Nieboer

iBMG, Erasmus Universiteit Rotterdam, Rotterdam,

Nederland

Prof.dr. R. S. Batenburg

NIVEL Utrecht, Utrecht, Nederland

Dr. P. P. Valentijn

Essenburgh, Hierden, Nederland

Dr. H. J. M. Vrijhoef

Huisartsgeneeskunde, Vrije Universiteit Brussel, Brussel, België

Panaxea bv, Amsterdam, Nederland

Prof.dr. C. A. Baan

RIVM, Bilthoven, Nederland

Prof.dr. R. S. Batenburg

Faculteit der Sociale Wetenschappen, Radboud Universiteit

Nijmegen, Nijmegen, Nederland teert het ministerie vier pijlers: zorgstandaarden, integrale bekostiging, het versterken van de samenhang tussen preventie en curatie, en zelfmanagement [1]. Meer dan tien jaar later zijn deze pijlers onverminderd belangrijk voor het ministerie. Ook het individuele zorgplan en zorggroepen worden hierbij ingezet [2]. De term 'programmatische aanpak' heeft het Ministerie van VWS inmiddels ingeruild voor 'netwerk- en ketenzorg' [3]. In dit artikel spreken wij over 'integratie van zorg', een term die een breed en internationaal gehoor vindt [4].

Recentelijk heeft de Wereldgezondheidsorganisatie (WHO) het belang van integratie van zorg nogmaals benadrukt in een wereldwijde oproep om ongewenste fragmentatie in gezondheidszorgsystemen tegen te gaan [4]. De WHO spreekt van een raamwerk waarin mensen een continuüm van gezondheidsbevordering, ziektepreventie, diagnose, behandeling, ziektemanagement, re-integratie en/of palliatieve zorg ontvangen, gecoördineerd tussen de verschillende niveaus en locaties van zorg binnen en buiten de gezondheidssector, en afgestemd op hun noden gedurende hun levensloop. Ten behoeve van de integratie van zorg onderscheidt de WHO vijf onderling afhankelijke strategieën:

- empowerment en het betrekken van burgers bij de zorg;

- het versterken van governance en verantwoording;

- het heroriënteren van het zorgmodel;

- het coördineren van diensten binnen en tussen sectoren;

- het creëren van een faciliterende omgeving [4].

Gezamenlijk dienen deze strategieën te resulteren in een betere gezondheid en gezondheidszorg voor alle burgers, inclusief verbeterde toegang tot zorg, verbeterde gezondheids- en klinische uitkomsten, betere gezondheidsvaardigheden en zelfzorg, toegenomen 
Tabel 1 Overzicht van subsidieprogramma's integratie van zorg

\begin{tabular}{|c|c|c|c|c|c|c|c|}
\hline Programma & Periode & $\begin{array}{l}\text { Budget } \\
(\mathrm{M} €)\end{array}$ & Doelstelling(en) & $\begin{array}{l}\text { Totaal aantal } \\
\text { projecten }\end{array}$ & $\begin{array}{l}\text { Aantal onder- } \\
\text { zoeksprojecten }\end{array}$ & Referentie(s) & $\begin{array}{l}\text { Betrokkenheid } \\
\text { auteur(s) }\end{array}$ \\
\hline Diabetes Ketenzorg & 2005-2010 & 2.925 & $\begin{array}{l}\text { Bevorderen organisatie van } \\
\text { diabeteszorg; bevorderen } \\
\text { diabeteseducatie }\end{array}$ & 14 & 10 & {$[30,31]$} & Baan \\
\hline $\begin{array}{l}\text { Disease manage- } \\
\text { ment }\end{array}$ & 2007-2012 & 17.998 & $\begin{array}{l}\text { Verbeteren van kwaliteit van } \\
\text { chronische zorgverlening door } \\
\text { het vormgeven van zorg voor } \\
\text { mensen met een (combinatie } \\
\text { van) chronische ziekte(n) door } \\
\text { multidisciplinaire (transmurale) } \\
\text { zorggroepen volgens disease } \\
\text { management-aanpak en het } \\
\text { Chronic Care Model }\end{array}$ & 46 & 24 & {$[32,33]$} & Nieboer \\
\hline $\begin{array}{l}\text { Nationaal Pro- } \\
\text { gramma Ouderen- } \\
\text { zorg }\end{array}$ & 2007-2016 & 89.000 & $\begin{array}{l}\text { Ontwikkelen van een integraal } \\
\text { zorg- en ondersteuningsaan- } \\
\text { bod op maat voor ouderen met } \\
\text { een complexe hulpvraag, dat } \\
\text { leidt tot betere zelfredzaam- } \\
\text { heid, meer functiebehoud, } \\
\text { minder zorggebruik en minder } \\
\text { zorg-/behandelbelasting }\end{array}$ & 204 & 42 & [34] & $\begin{array}{l}\text { Baan, Nieboer, } \\
\text { Vrijhoef }\end{array}$ \\
\hline Op één lijn & 2009-2014 & 16.625 & $\begin{array}{l}\text { Stimuleren organisatieontwik- } \\
\text { keling eerste lijn; evalueren } \\
\text { van proces van organisatieont- } \\
\text { wikkeling en samenwerking, } \\
\text { en verspreiden van goede } \\
\text { voorbeelden }\end{array}$ & 67 & 13 & {$[35,36]$} & $\begin{array}{l}\text { Batenburg, Nie- } \\
\text { boer, Valentijn, } \\
\text { Vrijhoef }\end{array}$ \\
\hline $\begin{array}{l}\text { Landelijke Monitor } \\
\text { Proeftuinen }\end{array}$ & 2013-2017 & NB & $\begin{array}{l}\text { In samenhang vormgeven } \\
\text { van preventie, zorg en welzijn } \\
\text { om de gezondheid van de } \\
\text { populatie en de kwaliteit van } \\
\text { zorg te verbeteren en de groei } \\
\text { in (zorg)uitgaven te beheersen }\end{array}$ & 9 & 9 & [37-39] & Baan \\
\hline
\end{tabular}

tevredenheid over de zorg, grotere arbeidstevredenheid voor zorgverleners, verbeterde doelmatigheid van zorgverlening en een afname van de totale kosten [4].

Met behulp van diverse (onderzoeks)programma's heeft het Ministerie van VWS, in samenwerking met de Nederlandse organisatie voor gezondheidsonderzoek en zorginnovatie (ZonMw), de ontwikkeling, toepassing en evaluatie van integratie van zorg gestimuleerd. Vier van deze programma's, waarin integratie van zorg expliciet op de voorgrond staan, hebben wij hier nader geanalyseerd: Diabetes Ketenzorg [5], Disease Management [6], het Nationaal Programma Ouderenzorg [7] en ten slotte Op één lijn (inclusief de evaluatiecommissie integrale bekostiging) [8]. In aanvulling hierop hebben wij ook de landelijke monitor proeftuinen population management geanalyseerd, die momenteel door het Rijksinstituut voor Volksgezondheid en Milieu (RIVM) [9] wordt verricht (zie tab. 1).

\section{Doelen}

Deze programma's leggen de focus op een of meer specifieke chronische ziekten (diabetesketenzorg en disease management), via doelgroepen (mensen die worden behandeld in de eerstelijnsgezondheidszorg en ouderen), naar een populatiebrede aanpak (proef- tuinen population management). Een dergelijke verbreding van focus past bij de essentie van integratie van zorg, waarin de noden van mensen als uitgangspunt worden genomen en een meer holistische kijk op gezondheid centraal staat $[10,11]$.

Ook is uit de doelstellingen van de programma's af te leiden dat integratie van zorg vooral tot stand dient te komen door het anders organiseren van het zorgaanbod en het vruchtbaar samenwerken van diverse belanghebbenden. Het belang van beide concepten ten behoeve van integratie van zorg is onomstreden. Voor het tot stand brengen van integratie van zorg zijn echter meer concepten voorhanden. Zo onderscheiden Van Houdt et al. veertien onderling gerelateerde theoretische concepten van coördinatie van zorg, waarvan 'organisatie' en 'samenwerking' er twee zijn [12]. Voorbeelden van andere concepten zijn 'externe factoren', 'kennis en technologie', 'uitwisseling van informatie', 'patiëntuitkomsten', 'teamuitkomsten' en '(inter)organisationele uitkomsten'. Ook volgens de zienswijze van de WHO zijn de programma's wat eenzijdig ingevuld en dient er (meer) aandacht te komen voor drie van de vijf strategieën, te weten: empowerment en het betrekken van mensen en groepen bij de zorg; het versterken van governance en verantwoording; en het creëren van een faciliterende omgeving. 
Het is opvallend dat, met uitzondering van de ontwikkeling in focus, bij de opeenvolgende reeks van programma's geen sprake is geweest van een (langetermijn)ontwikkelmodel voor integratie van zorg. Doordat vooral organisatie en samenwerking in alle programma's centraal zijn gesteld, is het de vraag of in de periode tussen 2005 en 2017 met dezelfde middelen niet meer had kunnen worden gedaan. Hiervoor had in ieder geval, vertrekkende vanuit een omvattende visie, meer nauwe, inhoudelijke afstemming tussen de programma's (en projecten) in de tijd moeten plaatsvinden. Wellicht dat de overlap in de looptijd van de verschillende programma's hierbij een belemmerende factor is geweest. De resultaten uit het ene programma waren immers nog niet compleet, terwijl het andere al van start ging. Uit de aanbevelingen die voortkomen uit de programma's blijkt duidelijk dat er een behoefte is aan een bredere insteek dan organiseren en samenwerken. Dit wordt hieronder nader toegelicht.

\section{Activiteiten}

De motivatie in het veld om deel te nemen aan de programma's was aanzienlijk; voor alle programma's geldt dat telkens gewerkt is met een selectie uit een groter aantal onderzoeks- en veldpartijen dat interesse toonde om deel te nemen. Een gering aantal partijen heeft aan meer programma's deelgenomen. Deelname aan een programma blijkt geen garantie voor deelname aan een opvolgend programma. Voor de Landelijke Monitor Proeftuinen geldt dat deelnemers zijn voorgedragen door zorgverzekeraars. Bij dit programma is, in tegenstelling tot de andere programma's, geen informatie voorhanden over de selectiecriteria en het selectieproces.

De nadruk op het anders organiseren van zorg en het verbeteren van de onderlinge samenwerking ter bevordering van integratie van zorg lijkt te zijn ingegeven door het praktijkgerichte karakter van de programma's, waarbij de invulling van de projecten grotendeels aan veldpartijen is overgelaten. Hoewel deze invulling aansluit op de doelstellingen van de programma's, is binnen de programma's sprake van een aanzienlijke mate van variatie in soort en aantal deelnemers, structuur- en samenwerkingsvormen, met gedeelde verantwoordelijkheid als de gemene deler. Geen van de programma's heeft alle vijf door de WHO beschreven strategieën geadresseerd en ook als alle programma's worden samengenomen is hiervan geen sprake.

Het is onduidelijk in hoeverre deze variatie is ingegeven door factoren als de noden van patiënten en/of de populatie, de mate van integratie van zorg bij aanvang van projecten (alsook hoe die tot stand is gebracht) en de beschikbare middelen. Door de beperkte programma- en projectduur kon niet altijd continuïteit worden geboden aan een ingezette ontwikkeling en het (langdurig) volgen ervan. Bij het pro- gramma Disease Management en het Nationaal Programma Ouderenzorg wordt aangegeven dat sprake is van borging van aangebrachte veranderingen, terwijl dit bij de programma's Diabetes Ketenzorg en Op één lijn juist als belangrijk punt van aandacht in de aanbevelingen wordt genoemd. De langere looptijd van het Nationaal Programma Ouderenzorg lijkt hierbij behulpzaam. Ook voor de borging is een langetermijnontwikkelmodel van integratie van zorg wenselijk.

\section{Evaluatie}

Voor de evaluatie van programma's is telkens sprake van (consortia van) externe, onafhankelijke evaluatoren (iBMG, Jan van Es Instituut, NIVEL, Regioplan, Research voor Beleid, RIVM, Universitaire Medische Centra). Deze evaluatoren, onder wie de auteurs van dit artikel (zie tab. 1), hebben vooral inzichten opgedaan vanuit de onderzoeksprojecten. Hoewel aannemelijk is dat de onderzoeksprojecten verweven zijn met de praktijkprojecten, zijn de inzichten uit de praktijkprojecten minder systematisch tot stand gekomen en/of gerapporteerd. Veelal is getracht antwoord te geven op de vraag óf integratie van zorg impact heeft op het zorgproces en de uitkomsten voor patiënten, zorgorganisatie(s) en het systeem. Daarbij zijn kwantitatieve en kwalitatieve data verzameld bij diverse stakeholders op verschillende meetmomenten in een tijdsperiode van twaalf tot 24 maanden. Uit de vraagstelling en de gekozen aanpak van de evaluaties blijkt dat men hoofdzakelijk wilde weten of integratie van zorg effectief is in termen van activiteiten en uitkomsten, die veelal zijn gebaseerd op bestaande richtlijnen of zorgstandaarden (black box-benadering). Indien sprake is van een effect- en een procesevaluatie zijn deze parallel aan elkaar verricht.

Op basis van de afgeronde evaluaties van de projecten van de diverse programma's wordt geconcludeerd dat integratie van zorg in sommige gevallen wel en in andere gevallen niet tot verbeterde processen en uitkomsten leidt en dat aanvullend onderzoek nodig is. Dit is typisch een gevolg van de toepassing van het traditionele format van experimentele onderzoeksmethoden op een complexe interventie die verschillende veranderingen op niet-lineaire wijze tot stand beoogt te brengen [13]. Ook de beperkte tijdspanne van de evaluaties draagt niet bij aan het ondersteunen van de besluitvorming omtrent integratie van zorg.

Bij de evaluatie van Disease Management en het Nationaal Programma Ouderenzorg zijn door de gehanteerde mixed methods-benadering wel diepgaandere inzichten verkregen. Hierbij wordt integratie van zorg meer gezien als een sociale innovatie, oftewel een multicomponentinterventie, die zich afspeelt in een complex, sociaal systeem. Daarop is de evaluatieaanpak geënt [13]. De traditionele black box-benadering is vervangen door een white box-benadering (zie het kader) [14]. Pas dan ontstaat antwoord op de vragen 


\section{De White box-benadering}

Bij de black-box-benadering worden alleen de effecten van een programma gemeten bij personen die aan het programma zijn blootgesteld. Hierbij worden a priori bepaalde uitkomsten gemeten. Eventueel waargenomen effecten in uitkomsten worden vervolgens toegeschreven aan het programma. Deze benadering is geschikt in een controleerbare setting waarin zo min mogelijk verstorende factoren aanwezig zijn. Een beperking van deze benadering is dat bij de evaluatie niet wordt gekeken naar de inhoud van het programma. Hierdoor blijft onbekend welke onderdelen van het programma wel en welke geen bijdrage hebben geleverd aan de (eventueel) waargenomen effecten, alsook waarom dit het geval is. Dit gebrek aan informatie belemmert het repliceren van de effecten. Ook bemoeilijk dit het (eventueel) verder verbeteren van het programma [14].

Als reactie hierop is de white box-benadering voor evaluatie ontstaan. In de alledaagse werkelijkheid waarin veel programma's worden gebruikt, kunnen verstorende factoren moeilijk of niet worden gecontroleerd. Daarom worden niet alleen uitkomsten gemeten, maar wordt ook gekeken hoe (eventuele) effecten tot stand komen en welke factoren hierbij een rol spelen. Hiervoor wordt gebruikgemaakt van een programmatheorie die gebaseerd is op veronderstellingen over de relatie tussen programma-inputs, mediërende factoren en programma-outputs. Aangezien deze theoriegedreven benadering beoogt de mechanismen bloot te leggen die maken dat een programma effectief is, wordt deze benadering white-box genoemd [14].

voor wie en wanneer integratie van zorg meer of minder effectief is. De informatie uit de programma's over de mate waarin integratie van zorg daadwerkelijk tot stand is gebracht, en in welke context, alsook over de invloed van factoren op de uitkomsten, en voor wie integratie van zorg meer of minder effectief is (ofwel een white box-benadering), is nu veelal nog te speculatief van aard. Uit de evaluatie van het Disease Management-programma is bijvoorbeeld wel inzichtelijk geworden dat het voor disease management-initiatieven gericht op patiënten die er ernstiger aan toe zijn, lastiger is om goede resultaten te behalen. Hieruit wordt vervolgens de les getrokken dat deze patiënten mogelijk meer baat hebben bij casemanagement of tweedelijnszorg dan de huidige disease managementinitiatieven in de eerstelijnszorg [15]. Ook de nog lopende evaluatie van de Landelijke Monitor Proeftuinen lijkt meer conform de white box-benadering te zijn opgezet [16].

Het belang van deze benadering, die internationaal bekend staat als Realist Evaluation [17], met gebruikmaking van geavanceerd mixed methods-onderzoek
[18], neemt toe naarmate sprake is van een bredere focus op integratie van zorg [19]. Het doel ervan is om patronen te onderzoeken en beter te begrijpen door exploratie van causale mechanismen die gevoelig zijn voor contextuele en sociale invloeden. Hierbij worden data verzameld over de mechanismen die ten grondslag liggen aan een complexe interventie, de context waarin de interventie wordt toegepast, de gegenereerde uitkomsten en de relaties tussen mechanismen, context en uitkomsten. Idealiter borduurt het toekomstige evaluatieonderzoek voort op de inzichten uit eerder onderzoek en is het gestoeld op theoretische concepten. De actieve betrokkenheid van alle veldpartijen hierbij is van groot belang, opdat zij de opgedane inzichten kunnen gebruiken voor continue verbetering van de kwaliteit van zorg in de dagelijkse praktijk [20].

Er is nog niet veel ervaring opgedaan met Realist Evaluation in de gezondheidszorg. Bovendien stelt deze benadering specifieke eisen aan onderzoekers, veldpartijen en beleidsmakers: afstemming en samenwerking tussen partijen moeten hand in hand gaan, waarbij onderzoekers bijvoorbeeld niet slechts op het eind van de evaluatieperiode hun inzichten delen of veldpartijen evaluatie als een activiteit of eis van anderen zien die hen niet aangaat [21].

\section{Aanbevelingen}

In de verschillende programma's is gedurende het tijdsbestek van 2005 tot op heden veel aandacht uitgegaan naar de organisatie van zorg en samenwerking. De grootste ontwikkeling die hierbij tot stand is gebracht, betreft de reikwijdte van integratie van zorg, die is verruimd van een of meer ziektebeelden naar de gezondheid van populaties. Desondanks is de lijst van concepten om integratie van zorg duurzaam in de praktijk te ontwikkelen en verankeren onverminderd groot. Voorbeelden hiervan zijn actieve betrokkenheid van patiënten, hun noden als uitgangspunt nemen, adequate financiering en prikkels, transparante informatieverstrekking en communicatie tussen alle betrokkenen, en passende (inter)organisationele governance. Al deze concepten worden in de diverse programma's van belang geacht voor een verdere ontwikkeling en/of borging van integratie van zorg. Ook van belang hierbij zijn het programmeren vanuit een overkoepelende, langetermijnvisie op integrale zorg, het uitzetten van langlopende programma's, waarbinnen regionale invulling noodzakelijk is, en het mogelijk maken van continuïteit in ontwikkeling binnen projecten (of regio's) en tussen programma's. Essentieel hierbij is dat alle stakeholders een actieve rol blijven spelen.

Gezien de uitdagingen van de landelijke proeftuinen is het niet realistisch te verwachten dat integratie van zorg in Nederland na afloop van dit programma in 2017 (twaalf jaar na de start van het programma Diabetes Ketenzorg) het gewenste niveau (en impact) 
heeft bereikt. Het evalueren van de bevorderende en belemmerende factoren, en de invloed hiervan op voorwaarden voor integratie van zorg, aan de hand van data afkomstig van de diverse programma's, kan een betekenisvolle bijdrage leveren aan de verdere ontwikkeling van integratie van zorg in Nederland. Door systematisch gebruik te maken van opgedane ervaringen en inzichten in de vorm van voor veldpartijen hanteerbare informatie, dient te worden voorkomen dat veldpartijen, inclusief beleidsmakers, hun aandacht, begrip en/of vertrouwen in de haalbaarheid en toegevoegde waarde van integratie van zorg verliezen [22].

Mogelijk kan een expertgroep het Ministerie van VWS helpen bij het duurzaam realiseren van integratie van zorg, in navolging van de Evaluatiecommissie Integrale Bekostiging, die tussen 2010 en 2012 het Ministerie van VWS heeft geadviseerd meer te doen om de vruchten van integrale bekostiging te kunnen plukken [23]. Deze groep zou kunnen beginnen met vaststellen waar we nu zijn en omschrijven waar we over vijf jaar willen uitkomen. Tussentijds kan ze helpen bepalen of de goede richting en snelheid worden aangehouden. Ondanks de aanhoudende roep om de onwenselijke fragmentatie van zorg uit te bannen, geven de opgedane ervaringen veldpartijen nog onvoldoende houvast bij het uitzetten van de juiste koers. Deze nieuw in te stellen commissie zou kunnen vaststellen wat we hebben geleerd van de diverse (onderzoeks)programma's, wat we nog steeds niet weten en hoe we aan de ontbrekende informatie moeten komen.

Buitenlandse ervaringen kunnen hierbij helpen. Net als in Nederland bestaat in andere landen, waaronder Australië, België, Engeland, Singapore en de Verenigde Staten, veel aandacht voor de vraag in welke mate integratie van zorg tot betere zorg leidt [24-28]. In de ontwikkeling van integratie van zorg en de evaluatie ervan speelt Nederland al jaren een toonaangevende rol. Zo worden onder aanvoering van de Wereldbank en de WHO goede praktijk- en onderzoeksvoorbeelden uit Nederland ter inspiratie gepresenteerd ten behoeve van de ontwikkeling en evaluatie van integratie van zorg in China [29].

Zowel voor de integratie van zorg als de evaluatie ervan geldt dat het onverminderd 'werk in uitvoering' is, waarbij de ermee gepaard gaande complexiteit een langetermijnvisie en -investering vereist. Vooral door de verdere ontwikkeling en implementatie van integratie van zorg meer vanuit een conceptuele basis vorm te geven en de evaluatie ervan af te stemmen op de relevante kennisvragen en de complexe aard van integratie van zorg wordt Nederland in staat gesteld blijvend een stempel te drukken op de noodzakelijke transformatie van gezondheidszorg in binnenen buitenland. Gebeurt dit niet, dan dreigt integratie van zorg slechts een ambitie te blijven van beleidsmakers, onderzoekers en een enkele zorgverlener die beseft dat meer van hetzelfde onvoldoende is voor een toekomstbestendige gezondheidszorg.

Dankbetuiging Bij het tot stand komen van deze tekst is dankbaar gebruikgemaakt van de inhoudelijke feedback van Renata Klop (adviseur bij ZonMw), Gerdie van Asseldonk (implementatiemedewerker bij ZonMw), Carlijn van Aalst en Karianne Jonkers (beiden programmasecretaris bij ZonMw).

\section{Literatuur}

1. Ministerie van Volksgezondheid, Welzijn en Sport. Programmatische aanpak van chronische zieken. Den Haag: Ministerievan VWS; 2008.

2. Rijksoverheid. Kwaliteit zorg bij chronische ziekte. 2017. https://www.rijksoverheid.nl/onderwerpen/kwaliteitvan-de-zorg/inhoud/kwaliteit-zorg-bij-chronischeziekte. Geraadpleegd op: 25 jul 2017.

3. Ministerie van Volksgezondheid, Welzijn en Sport. Rijksbegroting. 2017.

4. World Health Organization. Framework on integrated, people centered health services. 2016. http://apps.who. int/gb/ebwha/pdf_files/WHA69/A69_39-en.pdf. Geraadpleegd op: 25 jul 2017.

5. ZonMw. Diabetes Ketenzorg. 2017. http://www. zonmw.nl/nl/onderzoek-resultaten/kwaliteit-van-zorg/ programmas/programma-detail/diabetes-ketenzorg/. Geraadpleegd op: 25jul 2017.

6. ZonMw. Diseasemanagement Chronische Ziekten. 2017. http://www.zonmw.nl/nl/over-zonmw/ehealthen-ict-in-de-zorg/programmas/programma-detail/ diseasemanagement-chronische-ziekten/. Geraadpleegd op: 25 jul 2017.

7. ZonMw. Nationaal Programma Ouderenzorg. 2017. http://www.zonmw.nl/nl/over-zonmw/ehealth-en-ictin-de-zorg/programmas/programma-detail/nationaalprogramma-ouderenzorg/. Geraadpleegd op: 25 jul 2017.

8. ZonMw. Op één lijn. 2017. http://www.zonmw.nl/nl/ over-zonmw/ehealth-en-ict-in-de-zorg/programmas/ programma-detail/op-een-lijn/. Geraadpleegd op: 25 jul 2017.

9. RIVM. Duurzame preventie, zorg en ondersteuning. 2017. http://www.rivm.nl/Onderwerpen/D/Duurzame preventie_zorg_en_ondersteuning. Geraadpleegd op: $2 \overline{5}$ jul2017.

10. Redding D. The narrative for person-centred coordinated care. J Integr Care 2013;21:315-25.

11. Valentijn P. Rainbow of Chaos. A study into the theory and practice of integrated primary care. Doctoraalthesis. Tilburg: Tilburg University; 2015.

12. Houdt S van, Heyrman J, Vanhaecht K, et al. An in-depth analysis of theoretical frameworks for the study of care coordination. Int J Integr Care 2013. doi:10.5334/ijic.1068.

13. Berwick DM. The science of improvement. JAMA 2008;299:1182-4.

14. Salter KL, Kothari A. Using realist evaluation to open the black box of knowledge translation: a state-of-the-art review. Implement Sci 2014;9:115.

15. Nieboer AP. Houdbare zorg en ondersteuning in tijden van crisis. Inaugurele rede. Rotterdam: Erasmus Universiteit Rotterdam;2013.

16. Struijs JN, Drewes HW, Heijink R, et al. How to evaluate population management? Transforming the Care Continuum Alliance population health guide towards a broadly applicable analytical framework. Health Policy (New York) 2015;119:522-9. 
17. Pawson R, Tilley N. Realistic evaluation. London: SAGE; 1997.

18. Pawson R, Tilley N. Realist evaluation. 2004. http:// www.communitymatters.com.au/RE_chapter.pdf. Geraadpleegd op: 25 jul 2017.

19. Busetto L, Luijkx K, Vrijhoef HJM. Development of the COMIC Model for the comprehensive evaluation of integrated careinterventions. IntJCare Coord 2016;19:47-58.

20. Balasubramanian BA, Cohen DJ, Davis MM, et al. Learning evaluation: blending quality improvement and implementation research methods to study healthcare innovations. Implement Sci 2015;10:31.

21. Greehalgh T, Humphrey C, Hughes J, et al. How do you modernize a health services? A realist evaluation of whole-scale transformation in London. Milbank Q 2009;87:391-416.

22. Hendriks S, Kleefstra N, Warners J, Bilo H. Ketenzorg diabetes werkt wél. 2016. https://www.medischcontact. $\mathrm{nl} /$ nieuws/laatste-nieuws/artikel/ketenzorg-diabeteswerkt-wel.htm. Geraadpleegd op: 25 jul 2017.

23. Rijksoverheid. Eindrapport van de Evaluatiecommissie Integrale Bekostiging - Integrale bekostiging van zorg: Werk in uitvoering. 2012. https://www.rijksoverheid.nl/ documenten/rapporten/2012/06/26/eindrapport-vande-evaluatiecommissie-integrale-bekostiging-integralebekostiging-van-zorg-werk-in-uitvoering. Geraadpleegd op: 25 jul 2017.

24. NSW. Integrated carein NSW.2017. http://www.health.nsw. gov.au/integratedcare/pages/default.aspx. Geraadpleegd op: 25 jul 2017.

25. http://www.integreo.be/nl. Geraadpleegd op: 25 jul 2017.

26. NHS England. Spreading new care models. 2017. https://www.england.nhs.uk/ourwork/futurenhs/newcare-models/. Geraadpleegd op: 25 jul 2017.

27. Ministry of Health Singapore. Regional health systems. 2015. https://www.moh.gov.sg/content/moh_web/
home/pressRoom/Parliamentary_QA/2015/regional-healthsystems.html. Geraadpleegd op: 25 jul 2017.

28. CMS. State innovation models initiative: general information. 2017. https://innovation.cms.gov/initiatives/stateinnovations/. Geraadpleegd op: 25 jul 2017.

29. World Bank Group, World Health Organization, Ministry of Finance, National Health and Family Planning Commission, Ministry of Human Resources and Social Security. Healthy China: deepening health reform in China. Washington DC: World Bank Group; 2016.

30. ZonMw. Diabetes Ketenzorg. 2017. http://www.zonmw.nl/ $\mathrm{nl} /$ programmas/programma-detail/diabetes-ketenzorg/ algemeen/. Geraadpleegd op: 25 juli 2017.

31. RIVM. Experimenteren met de keten-dbc diabetes. De eerste zichtbare effecten. Bilthoven: RIVM;2009.

32. http://www.zonmw.nl/nl/programmas/programma-de tail/diseasemanagement-chronische-ziekten/algemeen/. Geraadpleegd op: 25 juli 2017.

33. Cramm JM, Tsiachristas A, Adams SA, et al. Evaluatie van disease management programma's in Nederland. Rotterdam: EUR, Instituut BMG;2014.

34. ZonMw. Beter oudworden. 2016. http://www.beteroud.nl/ docs/beteroud/over-ons/krachtboekje-npo.pdf. Geraadpleegd op: 25 juli 2017.

35. http://www.zonmw.nl/nl/programmas/programma-de tail/op-een-lijn/algemeen/. Geraadpleegd op: 25 juli 2017.

36. ZonMw. Evaluatie programma Op één lijn. Den Haag: ZonMw; 2015

37. Rijksoverheid. Kamerbrief over proeftuinen en pilots 'betere zorg met minder kosten'. 2013. https://www. rijksoverheid.nl/documenten/kamerstukken/2013/04/ 23/kamerbrief- over-proeftuinen-en-pilots-betere-zorgmet-minder-kosten. Geraadpleegd op: 25 juli 2017.

38. RIVM.Landelijkemonitor proeftuinen. Deel 1: beschrijving proeftuinen. Bilthoven: RIVM; 2014.

39. RIVM. Samenwerken aan duurzamezorg. Landelijkemonitor proeftuinen. Bilthoven: RIVM; 2015. 